Meta

Journal des traducteurs

Translators' Journal

\title{
Semantic Orientation, Syntactic Position and Pragmatic Function of Modifier in Chinese-English Translation
}

\section{Huawen Liu}

Volume 54, numéro 1, janvier 2009

URI : https://id.erudit.org/iderudit/029797ar

DOI : https://doi.org/10.7202/029797ar

Aller au sommaire du numéro

Éditeur(s)

Les Presses de l'Université de Montréal

ISSN

0026-0452 (imprimé)

1492-1421 (numérique)

Découvrir la revue

Citer cet article

Liu, H. (2009). Semantic Orientation, Syntactic Position and Pragmatic Function of Modifier in Chinese-English Translation. Meta, 54(1), 131-145.

https://doi.org/10.7202/029797ar

\section{Résumé de l'article}

Dans la traduction du chinois vers l'anglais, les équivalents des modificateurs du nom ou du verbe sont souvent sujets à un redéploiement dans la langue cible. En vertu du principe selon lequel un modificateur doit être situé syntaxiquement dans l'immédiateté du modifié vers lequel il est sémantiquement orienté, le déplacement d'un modificateur depuis sa position syntaxique de base est provoqué par des facteurs pragmatiques. Toutefois, dans le contexte de la traduction chinois-anglais, le modifié peut exercer une force d'attraction accrue sur le modificateur. En conséquence, le modificateur initialement déplacé, et donc en position identique à celle de son équivalent anglais, retourne dans une position proche du modifié, le nom ou le verbe, vers lequel il est sémantiquement orienté. Ou encore, le modificateur réintègre la position syntaxique le plus près du nom ou du verbe qu'il modifie. L'analyse conclut de manière convaincante que la force de gravité du modifié dans la traduction chinois-anglais est le fruit d'un accroissement des préoccupations sémantiques du traducteur, bien que certains effets pragmatiques, attendus ou inattendus, puissent aussi être produits.
Ce document est protégé par la loi sur le droit d'auteur. L'utilisation des services d’Érudit (y compris la reproduction) est assujettie à sa politique d'utilisation que vous pouvez consulter en ligne.

https://apropos.erudit.org/fr/usagers/politique-dutilisation/ 


\title{
Semantic Orientation, Syntactic Position and Pragmatic Function of Modifier in Chinese-English Translation
}

\author{
H UAW EN LI U \\ Nanjing University, Nanjing, China \\ shl0068@sina.com
}

\begin{abstract}
RÉSUMÉ
Dans la traduction du chinois vers l'anglais, les équivalents des modificateurs du nom ou du verbe sont souvent sujets à un redéploiement dans la langue cible. En vertu du principe selon lequel un modificateur doit être situé syntaxiquement dans l'immédiateté du modifié vers lequel il est sémantiquement orienté, le déplacement d'un modificateur depuis sa position syntaxique de base est provoqué par des facteurs pragmatiques. Toutefois, dans le contexte de la traduction chinois-anglais, le modifié peut exercer une force d'attraction accrue sur le modificateur. En conséquence, le modificateur initialement déplacé, et donc en position identique à celle de son équivalent anglais, retourne dans une position proche du modifié, le nom ou le verbe, vers lequel il est sémantiquement orienté. Ou encore, le modificateur réintègre la position syntaxique le plus près du nom ou du verbe qu'il modifie. L'analyse conclut de manière convaincante que la force de gravité du modifié dans la traduction chinois-anglais est le fruit d'un accroissement des préoccupations sémantiques du traducteur, bien que certains effets pragmatiques, attendus ou inattendus, puissent aussi être produits.
\end{abstract}

\begin{abstract}
In Chinese-English translation the equivalents for noun or verb modifiers are more than often subject to redeployment in the target language. According to the principle that a modifier is supposed to be syntactically located in the immediacy of the modified toward which it is semantically oriented, the displacement of a modifier from where it should be syntactically located is incurred because of pragmatic motivations. However, in the context of Chinese-English translation, the modified can exert more drawing force on the modifier. As a result, the originally displaced modifier, now in a position identical to that of its English equivalent, returns to the modified, the noun or the verb, toward which it is semantically oriented. Or the modifier will resume the syntactic position as close to its modified noun or verb as possible. A conclusive analysis claims that the drawing gravity from the modified in C-E translation results from the translator's heightened semantic concerns, although some pragmatic effects can be produced as expected or unexpected.
\end{abstract}

MOTS-CLÉS/KEYWORDS

Chinese-English translation, semantic orientation, syntactic position, pragmatic function

\section{Semantically oriented verb or noun modifiers and their syntactic dislocation in Chinese}

The semantic relationship between lexical units in Chinese has been the focus of investigations conducted by Chinese grammarians. The semantic orientation theory is one of the theoretical approaches to the manner by which a lexical unit is related to 
the other units. Among the inter-unit relationships the connection between a modifier and its modified nominal or verb usually attracts the attention of the theory.

In view of the syntactic property, the phenomenon of 'semantic orientation' demonstrates itself in another category: the oriented relationship between the modifier and the modified (for instance, adverbial and its modified verb, adjective and its modified noun). (Lu and Shen 2004: 283)

In the semantic characterization of a modifier, it can be detected that there must be something corresponding to be modified by the modifier. In other words, a modifier is supposed to be semantically oriented towards the modified.

In the light of Dependence Grammar by Tesniere (see Shen and Zheng 1996), a French grammarian, the lexical units in a sentence are inter-dependent, and how they differ from each other is in their varying degrees of dependence. In comparison, a noun can relatively stand alone owing to its semantic self-containedness. A verb is much more semantically parasitic, though it does not display this parasiticness in semantic orientation. Instead, a verb interacts with one or more valences. Then we have one-valence, two-valence, and even three-valence verbs. The valences are nothing but elements a verb relates itself to and thus they are what it refers to. In comparison, a modifier does not relate itself to the modified as a verb does to its valences. However, a modifier is supposed to have the vehicle of its modified target. What serves as the vehicle of the target is an entity or an action, or in terms of syntactic category, a noun or a verb, towards which the modifier is supposed to be semantically oriented. The connection between lexical items in a sentence has constituted a semantic network. In the network, "the lexical items in a sentence are not semantically connected in a one-way and fixed-up manner; rather, they are multi-directionally connected on the basis of the central dependent relationship between the verb and its arguments." (Zou 2000: 122) The multi-directionality and hence the indeterminacy renders the semantic relationship between lexical items susceptible to the shift of their syntactic position. This is more typically illustrated by the mismatches between the semantic orientation of a modifier and its syntactic position relative to the verb or noun it modifies.

In Chinese, modifiers mainly fall into two categories: the type modifying action and the type modifying entity. An action modifier usually finds itself in the syntactic position of adverbial before a verb, which can be illustrated in the following sentence:

(1) 他早早地炸了盘花生米。

(He has already fried a plate of peanuts.)

In this sentence, “早早地(literally, early)” is the modifier of the action “炸(fry)” and immediately positioned before the action it intends to modify as an adverbial. Semantically, this kind of modifiers is oriented towards action while, syntactically, it serves as an adverbial immediately positioned before a verb. Its semantic orientation predetermined its syntactic position. An action modifier corresponds with its positioning ahead of a verb.

Another kind of modifier in Chinese is employed to modify the entities. Their corresponding syntactic position is generally located before the nouns signifying the entities they modify. For example: 
(2) 他炸了一盘脆脆的花生。

(He has fried a plate of crispy peanuts.)

In this sentence, “脆脆的(crispy)” is a noun modifier and semantically refers to one of the properties of peanuts, which determines its being positioned before the noun it modifies as an attribute. However, the removing of “脆脆” from the noun-attribute position to that of verb-adverbial is also acceptable as embodied by the following sentence:

（3）他脆脆地炸了一盘花生。

(He has crisply fried a plate of peanuts.)

Here, the position corresponding to the noun modifier has undergone relocation. The modifier originally positioned before the verb is shifted to the position before the noun. And similarly, the noun modifier supposedly placed before noun can also be shifted to the position before the verb. The corresponding syntactic position of a modifier is supposedly in conflict with its semantic orientation. This syntactic anomaly is at odds with the principle according to which semantically a verb-oriented modifier is located in the vicinity of the modified verb while a semantically nounoriented modifier is located in the vicinity of the modified noun. The violation of this principle in daily speech acts is further shown by one more example listed below:

(4) 他喝了一杯猛酒。

(To the effect: He has drunk a cup of violent alcohol.)

Generally, “猛(violent)" is a verb-oriented modifier which is supposed to be positioned close to the verb. Its semantic orientation anticipates the utterance of the following sentence:

(5) 他猛喝了一杯酒。

(He has violently drunk a cup of alcohol.)

In this sentence “猛” is immediately placed before “喝(drink)," the verb towards which it is oriented. In the syntactic dislocation of the noun or verb modifiers, it is often found that the changes are pragmatically motivated. Zhang Guoxian (2005) has given three pairs of pragmatic motivations that lead to the dislocation of noun or verb modifiers:

\subsection{Perpetuity and temporariness}

In Chinese, syntactic position determines the temporal property of a modifier. Language and its components on various levels are related to time, which is ubiquitous in the aspects of human life. An entity finds itself in time from the very beginning of its presence in the world. An action is a sequential progress confined in time. The modifier of an entity-noun or an action-verb takes up temporal properties as soon as it is put in the syntactic sequence. Among the temporal properties, perpetuity and temporariness are the "general cognitive mechanisms" (see Zhang Guoxian 2005: 21). A modifier as the attribute for a noun is the perpetual descriptive property while a modifier as the adverbial for a verb is the temporary descriptive property. The positional shift of a modifier as demonstrated in the shuttle from attribute to adverbial can engender the assuming or the shedding of either of the two temporal properties: 


\section{(6) 狡猾的敌人逃跑了。}

(The cunning enemy has escaped.)

In this sentence, the modifier “狡猾(cunning)” as an attribute for “敌人(enemy)” is the perpetual property of “敌人.” But its shift from the position before noun can evoke the shedding of perpetuity just as the following sentence does:

(7) 敌人狡猾地逃跑了。

(The enemy has escaped cunningly.)

As the result of the positional shift of “狡猾," “敌人” escaped owing to their “tactics” which came into being temporarily just at the very moment of their escape. In comparison with the last sentence, the modifier “狡猾” is more an impromptu property than a perpetual one. The positional shift within one language is also a cross-lingual occurrence, whereby the change is engendered in terms of temporality despite occasional subtlety in the change.

\subsection{Intentionality and unintentionality}

The positional shift of a modifier can also invoke a change in the degree of intentionality. If positioned before a noun as an attribute, the modifier serves as a perpetual property of the entity. Perpetuity hinders the entity form possessing a large space to manipulate the property. In contrast, when the modifier is relocated into the position before a verb as an adverbial, the agent of the action will be assigned more freedom to put the modifier-carried property under control. With this viewpoint into the syntactic shift, we are lent an interpretive power to account for the shift of a modifier in the following sentences:

(8) (a) 孩子在沙滩上挖了一个深深的洞。(Zhang 2005: 23)

(The child has dug a deep hole in the sands.)

(b) 孩子在沙滩上深深地挖了一个洞。(Zhang 2005: 23)

(The child has deeply dug a hole in the sands.)

In sentence (a), the depth of the "hole" is created with two possibilities: it is unintended or intended. Despite the two possibilities, it is more likely for the unintentionality to serve as the property of “洞.” But in (b) “深深地” is more likely to imply the children's salient intention to dig the hole deep. Though the two “深深” are semantically oriented towards “洞," the difference in syntactic position incurs a delicate alteration in terms of intentionality.

\subsection{Subjectivity and objectivity}

In correspondence to the degrees of intentionality embodied respectively by the attribute-modifier and the adverbial-modifier, the positional shift can also result from the degree of the involvement of the speaker in the discourse construction. If the speaker has great presence in the construction, they are subjectively involved; if he/ she has little presence, they are objectively involved. The degree of involvement by the speaker can be syntactically embodied by the position of a modifier. The preverbal positioned modifier is the vehicle of subjectivity while the pre-nominal positioned modifier is that of objectivity: 
(9) (a) 主人沏了一杯浓浓的咖啡。 (Zhang 2005: 23)

(The host has made a cup of heavy coffee.)

(b) 主人浓浓地沏了一杯咖啡。(Zhang 2005: 23)

(The host has fragrantly made a cup of coffee.)

When positioned before “咖啡(coffee)” towards which “浓浓(heavy)” is semantically oriented, the modifier is stripped of subjective intention with which the action “沏 (make)" is conducted. The relatively perpetual property denies the subjective involvement and rather distances the speaker from the statement. But in (b), the necessity of emphasizing the subjectivity summons the removal of “浓浓” from where it is supposed to be to the position before the verb “沏.” In this way the action is performed with more subjective intention than that in (a). Then sentence (b) has achieved the pragmatic effects while (a) is stated with the absence of this effect.

The three pairs of pragmatic concerns discussed above imply that the shifts of syntactic position for modifiers do not arise from nothing. Rather, the syntactic anomaly can be justified by the pragmatic motivation of the statement maker. In the light of the syntactic shifts and their respective pragmatic effects, we are more authorized to account for the cross-lingual shifts in the Chinese-English translation. It is anticipated how the shifts concerned with modifiers with respect to their semantic orientation and syntactic position are justified for C-E translation in the following parts of this essay.

\section{The syntactic zero-redeployment of verb-modifiers in C-E translation}

Verb or noun modifiers in C-E translation more often than not yield to several rearrangements in English. The most frequent redeployment is demonstrated in the regular modifier-positioning in correspondence with the source text. The equivalent modifier is positioned as its counterpart in the source sentence. What is originally located in the regular way is also located in the regular way as the target language requires, and what is originally dislocated is still to be aligned into the regular syntactic position as the semantic-syntactic correspondence principle dictates.

(10) 围在短墙外看光景的孩子们都哈哈大笑。(Mo 2001: 3)

Some kids sprawled atop the wall hooted gleefully. (Goldblatt 2003: 6)

(The lexical units in both Chinese and English sentences are italicized by the author of the essay for attention, and this is also practiced in the following examples.)

In the Chinese version of the sentence from Red Sorghum by Mo Yan, “哈哈 (gleefully)" is the pre-verb modifier which semantic orientation and syntactic position accord with each other. In the English version, the translator does nothing to the verb-affiliated modifier and retains its syntactic position as it originates from. This type of syntactic redeployment can be called zero-redeployment. The zero-redeployment frequently occurs when the semantic orientation of a modifier corresponds to its syntactic position in the source sentence. In the rendered version, this correspondence survives the translation with the syntactic sequence undisturbed, though, in English, an adverbial modifier usually finds itself behind the verb while in Chinese before the verb. Following this approach to the redeployment of modifier and its modified, the translation as exemplified below is also performed.

(11) 父亲前边那个人吭吭地咳嗽起来。(Mo 2001: 3)

The man in front of Father coughed loudly. (Goldblatt 2003: 5) 
What “吭坑地(loudly)” describes is the way “the man in front of Father” coughs rather than "the man in front of Father" per se. Then it is not necessary to rearrange its position by detaching itself far away from the verb "cough." Thus the English equivalent for “吭坑地” remains where it is syntactically in the source sentence. Thus it is placed after "coughed" as an English verb modifier regularly finds itself.

The location of a verb-modifier is subject to no change, as a result of which its semantic orientation corresponds to its syntactic position just in the way it originally does. If the two correlates are dislocated in the source text, it is also likely for the modifier to be syntactically dislocated just as it does in the original sentence. The retaining of dislocation is illustrated by the following translations:

(12) 王文义欢欢喜喜地䠌着脚, 不知转到哪里去了。(Mo 2001: 3)

Wang Wenyi stomped down joyfully, but where he intended to 'face' was anyone's guess. (Goldblatt 2003: 6)

（13）他极不情愿地把骡子缰绳交给了一个烂眼圈的老头子。(Mo 2001: 14)

He reluctantly handed the mules over to an old geezer with festering eyes. (Goldblatt 2003: 18)

In Chinese sentences (12) (13), though we can say that “欢欢喜喜(joyfully)” and “极 不情愿(reluctantly)” are intended to delineate the manner the two acts “䠌着脚 (stomp)" and “交给(hand)" are respectively performed, they actually are more drawn to the act performers. But they deny the rectification of syntactic position and thus remain where they are in the English versions.

\section{The cross-lingual relocation of verb modifiers in Chinese-English translation}

\subsection{Position-retaking of modifiers in C-E translation}

\subsubsection{Position-retaking of modifier before the noun as subject}

In $\mathrm{C}$-E translation, the equivalence on the level of lexicon does not necessarily ensure the correspondence in syntactic position of two equivalent lexical units. As for a verb or noun modifier, its syntactic position in the original sentence can survive the translation and remain in the target sentence as it is originally located. The inconsistence between the semantic orientation and the syntactic position can be rectified in the process of translation. Upon rectification, a verb-oriented modifier resumes the syntactic position it is supposed to assume in the source sentence. Similarly, a noun-oriented modifier returns to the locus where it should be in the original sentence. The return of a pre-verb positioned modifier to the position its semantic orientation designates occurs in the translation of the sentence below:

(14) 父亲应了, 余司令就牟着他的手走。王文义哼哼唧唧地跟在后边。(Mo 2001: 9) Father answered, and Commander Yu walked off holding him by hand, followed by the whimpering Wang Wenyi. (Goldblatt 2003: 12)

In the source sentence, “哼哼唧唧” as a verb-modifier is semantically oriented towards “王文义,” though it is not immediately positioned before “王文义.” This misplacement has undergone rectification in translation. We can find that "whimpering," the English equivalent for “哼哼唧唧,” has reassumed its syntactic position as 
its semantic orientation designates. This retaking of the syntactic position before the subject in the original sentence also occurs for the modifiers in the translation of the following sentences:

(15) 骡子愤怒起蹄, 明亮的蹄铁跑起泥土, 溅了伪军一脸。(Mo 2001: 13)

The angered animal pawed its ground with its rear hooves, its metal shoes glinting in the mud that sprayed the soldier in the face. (Goldblatt 2003: 17)

(16) 日本兵愕然止步。(Mo 2001: 13)

The startled Japanese soldier froze. (Goldblatt 2003: 17)

(17) 由于丁问渔连续两天都是魂不附体地出现在任府, 大家以怀旧的心情, 开始大谈 丁问渔。(Ye 2002: 77)

Because for the last two days in a row, Ding's old distraught self had appeared at the Ren compound, everyone started talking about him with a feeling of nostalgia. (Berry 2004: 87)

\subsubsection{Position-retaking of modifier before the noun as object}

The shift of modifier can be directed towards the noun as object. The syntactically misplaced modifiers tend to be rectified by assuming the part of speech as an attribute before their modified nouns. In terms of syntactic relation, a noun can be either a subject or an object. In a general sense, the noun-oriented modifiers tend to return to the nouns as subjects. But occasionally they are oriented towards the nouns as objects in the original sentences, though some nouns are likely to be shifted to the position of subject as a consequence of translation, just as the translation of the following sentence does:

(18) 父亲感到公路就要到了, 他的眼前昏昏黄黄地晃动着路的影子。(Mo 2001: 7)

Father sensed that the highway was just ahead, its pale-yellow outline swaying in front of him. (Goldblatt 2003: 10)

The Chinese sentence is subject-absent. “昏昏黄黄” is semantically oriented towards “影子” despite the fact that it is syntactically positioned before the verb “晃动.” Due to the inconsistency the translator is more likely to rectify the "mislocation" by shifting the modifier back to the position before the object-noun. Hence, "pale-yellow," the original verb-modifier, is situated before "outline." As a result, the syntactic identity of "pale-yellow" has changed from the original verb-adverbial to the nounattribute.

The shift-back of noun-oriented modifiers to the object-noun is typical of the following version of a sentence:

(19) 我这会却又不饿了, 一点胃口都没有, 什么也吃不下, 只是一小口一小口地喝咖啡。 这杯咖啡里有股化学味道, 像在喝家具亮光剂。(Wei 1999: 151)

Suddenly, I had no appetite at all. I couldn't eat anything and just sipped a few mouthfuls of coffee, which had a chemical taste, like furniture polish. (Humes 2001: 153)

In the Chinese version, “一小口一小口” denotes the amount at which “我” drinks coffee. So semantically speaking, it is more attached to “咖啡.” Then it has shifted backwards into the attribute position before the noun as the object. 


\subsection{Mutual merging of a modifier and the modified: verb-inclined and modifier-inclined blending}

\subsubsection{Verb-inclined blending}

If a verb modifier and the verb are semantically close enough, it is more likely for them to merge into each other. The blending is often performed by attributing the originally modifier-possessed properties to the verb. We can call this blending verbinclined blending. For example,

(20) 雨媛注意到有人从馆子里东倒西歪地走出来, (Ye 2002: 146)

As they casually chatted, Yuyuan noticed a man who staggered out of the restaurant...

(Berry 2004: 185)

In this translation, the verb absorbs its modifier into itself and thus the previous power of the modifier has been diminished with its fade-out into the verb it originally modifies. The binding of the modifier and the modified is rendered possible owing to the fact that the modifier is semantically oriented toward the modified, i.e., the verb. This leads to the decomposability of the rendered merged verb.

The verb-inclined blending can result in the perpetualization of some properties of the modifier to be blended as illustrated in the translation of this Chinese sentence:

(21) 一个工人模样的中国人, 用手中持着的紫红色的藤条, 轻轻戳翟罗汉大爷的头,

说 [...] (Mo 2001: 14)

Where a Chinese overseer tapped him on the head with a purplish rattan whip and said, [...] (Goldblatt 2003: 18)

The originally temporary property of the modifier "轻轻(lightly)" has been merged into the verb "tap," which is perpetually embedded with the property "lightly." "Lightly" as perpetual property inherent in "tap" can be inferred from the definition given by The Random House Dictionary of English Language (second edition): "tap: 1. to strike with a light but audible blow or blows; hit with repeated, slight blows."

Obviously, the two parts of the first sense for "tap" as a verb have taken up "lightness" or "slightness" as their indispensable property. In comparison with the property perpetually inherent within this verb, the originally pre-attached modifier "轻轻” tends to be an impromptu and temporary property of the verb “翟翟.” The relocation of the modifier performed by the translator through verb-inclined blending leads to the diminishment of the temporariness as the property of the original verb and the upgrading of the perpetuity as the property of the post-blending verb in the target language.

The merging of the properties possessed by a modifier into the modified can also be partial. In this case, the rendered verb partially takes up the properties in the original modifier while the rendered modifier preserves the left-outs. In the English version of the following sentence, "weakly" as the adverbial modifier and "drag" as the modified partake of the properties that “筋疲力尽” embraces:

(22) 我筋疲力尽地从床上爬起来时阳光已照彻屋内。(Wang 2004: 58)

Long after the sun's rays had filled the room, I dragged myself weakly out of bed. (Goldblatt 1997: 95)

The verb "drag" suggests that "I" is at the end of strength, representing the original scene reified in “筋疲力尽." This representation cannot be achieved by "weakly" 
alone, for “weakly" is less than “筋疲力尽” in terms of degree. In the meantime, the compensation for the reduced strength falls on the shoulder of "drag." In this sense, partial properties embraced by “等疲力尽” have been shifted to “drag”; in other words, partial verb-inclined blending happens to the translation.

\subsubsection{Modifier-inclined blending}

In addition to the verb-inclined blending for the semantically action-oriented verb modifiers, it is also likely for one to execute modifier-inclined blending in translation. In this case, the verb-represented action will disappear into the background of the scene characterized by the sentence; meanwhile, the modifier is zoomed in and attains salience through being transformed into an action.

This type of blending inclined to the modifier is usually implemented by the verbalization of the modifier in compensation for the absence of the verb, the modified, due to being blended. The disappearance of the equivalent for the original verb is not complete, for some semantic residues of the verb can still be detected in the modifier in the identity of verb. In the coming example, "towering," as the verbalized result of “高高," has absorbed "stand" into itself, although this semantic component is far from prominence as in the original “站”:

(23) 他顶着一头金发, 高高地站在我面前, [...] (Wei 1999: 58)

I saw Mark, with his golden crown, towering in front of me. (Humes 2001: 60)

In the modifier-inclined blending by verbalization of the modifier, the semantic residues of the original verb can be preserved in the verbalized modifier. If they are not present by preservation, they can be accessed by inference from the other components in the sentence. In the translation of the following sentence, the translator renders “沙沙地下” into “pitter-patter," where the sound is foregrounded while “下” has lost its whereabouts. However, the action can also be inferred by relating the sound of pitter-pattering to its source, i.e., the rain. Then the absence of the verbcarried action because of the modifier-inclined blending is retrieved through contextual inference.

(24) 手机的效果也不十分好, 听上去像在沙沙地下冷雨。(Wei 1999: 48)

And because the connection wasn't very good, it sounded as if cold rain was pitter-pattering in the background. (Humes 2001: 50)

\subsubsection{One-party blending by annulment}

In a general sense, blending usually involves two members: the modifier and the modified. But sometimes we can run into a blending only involving one party, with the other one left out. This type of blending is a frequent occurrence to the modifier as the accompanied action for the modified. For example, in the following translation:

(25) 丁问渔忘乎所以地说着。(Ye 2002: 169)

Ding Wenyu got completely carried away. (Berry 2004: 213)

“忘乎所以” is semantically oriented towards “丁问渔.” The modifier is quite detached from the modified "说” due to their semantic-syntactic inconsistence. Then in the English version, the modified has become absent as it is merged into the modifier. 
This blending is often brought about by the lesser cohesion between the modifier and the modified in view of their semantic orientation and misplaced syntactic position. Moreover, the modifier has to undergo verbalization with the disappearance of the original verb.

In a similar vein, the modifier loaded with the accompanied action for the verb usually displaces the verb from the translation. It seems that the modifier is not syntactically subordinate to the modified. But rather, it enjoys much higher salient status. The following sentence is translated with the result that the original modifier is verbalized with nothing reserved for the semantic contents of the original modified.

(26) 当女儿发泄完了她的仇恨以后, 张氏叹着气说, 女儿这么做也许是对的, (Ye 2002:

Once her daughter began to calm down a bit, Mrs. Zhang sighed; she knew that Little Moon was right. (Berry 2004: 193)

\subsection{The tension between the centrifugal force of semantic orientation and the syntactic gravity of the modified}

When the verb modifier is not originally oriented towards the verb before which it is immediately placed, the possibility is rather high that the modifier and its modified be torn apart. In the following Chinese sentence, “大声” as the modifier of “划拳” is actually oriented towards “人," the utterer of the sound as well as the agent of the action. It is more closely related to the noun than to the verb, although the verb is immediately positioned after it. This inconsistence between the syntactic position and the semantic orientation has evoked the grammatical fact that the noun exerts more semantic gravity onto the modifier than the verb. Then it is rather justifiable that the translator of this sentence has pulled the verb modifier and its modified verb apart in the following way:

(27) 有几个人在大声划拳, (Ye 2002: 146)

There were a few people making a hubbub as they played finger-guessing games over their ale. (Berry, 2004: 185)

In the source sentence, “大声” as the modifier of the verb “划拳” is inferiorly attached to the latter. It enjoys less cognitive salience against its modified. But the translator has pulled apart the modifier and the modified by making the former separate from the latter and thus letting it stand as an independent sentential section on par with “划拳," which is rendered into "they played finger-guessing games over their ale." Unfortunately, this part has been relegated into the status of a clause while the original modifier has been elevated into a focal area.

The tendency to return to the position the modifier is supposed to be in can be actualized by the rip-off of the modifier itself and the modified. Although the return cannot bring the modifier to the very position before the semantically oriented lexical unit, it can demonstrate its denial against the gravity exerted on it by its original modified.

(28) 在另一个房间里, 在一堆器械中我看到我的表姐在汗淡淡地跑步。(Wei 1999: 48)

In another room I found my cousin amid a mass of equipment, sweating heavily as she jogged on the treadmill. (Humes 2001: 50) 
The semantic orientation and syntactic position do not correspond to each other as the correspondence principle requires in the source sentence. “汗涔涔” has more semantic affinity to “我的表姐” in terms of semantic value, for “she” is the very person that perspires in the physical activity. The semantic orientation of the adverbial modifier lends itself the centrifugal force to churn away from “跑步.” In translation, this force finally prevails over the syntactic gravity from the modified, and consequently the original modifier presents itself as a present participle with "as" inserted between the modifier and the modified, which is reduced to positioning in a subordinate clause.

The as-inserting way of syntactic isolation of the modifier from the modified incurred by their semantic-syntactic inconsistence is a frequent case in C-E translation. In addition to the above-mentioned example, we can have this one as an illustration of the as-inserting isolation:

(29) 黄酒从他嗓子眼里流了进去, 暖融融地流了进去, (Yu 2004: 11)

The wine flowed down his throat, warming his insides as it went, (Berry 2004: 14)

“暖融融” is supposed to be semantically oriented toward “黄酒.” But it is syntactically "mislocated" into the position immediately before “流." The translator takes advantage of this "mislocation" by realigning their modifying relation into a present participle followed by a temporal clause. The realignment is attributed to the successful wrench-out of the modifier from its adverbial position with the help of the centrifugal force, before which the syntactic gravity exerted by the modified is dwarfed.

Originally inconsistently located relative positions between a modifier and its modified verb make it more likely for the former to distance itself from the latter in translation. For the semantically noun-oriented modifier which is syntactically positioned before the verb, the translator tends more to remove it from its original position and relocate it at a position more attached to the entity it is semantically oriented to. Hereby, we have a Chinese sentence with an illustration of this relocation when it is translated into English.

\section{The pragmatic effects of re-matches in the semantic-syntactic relationship of modifiers in C-E translation}

According to Croft (1991), each type of lexical unit (in his term, syntactic category) prototypically corresponds to a pragmatic function. He has singled out three types of syntactic categories for study: noun, verb, and adjective. And more than that, in the light of his typological study, the three categories are assigned their prototypical pragmatic functions respectively: reference, predication, and modification (see Croft 1991: 51-52). In comparison with the other two functions:

... modification appears to be largely an accessory function to reference and predication: restrictive modification helps fix the identity of what one is talking about (reference) by narrowing the description, while nonrestrictive modification provides a secondary comment (predication) on the head that it modifies, in addition to the main predication. (Croft 1991: 52)

As inferred from the statement, restrictive modification denotes the pragmatic role played by the noun modifier while the nonrestrictive modification denotes the pragmatic role played by the verb modifier. The two roles are consistent with the pragmatic 
motivations for the positioning of modifiers given by Zhang Guoxian: perpetuity, which is restrictive, and temporariness, which is nonrestrictive (see the first part of this essay). With this pair of pragmatic motivations, the other two couples are dug out on the part of speech performer, who is motivated to achieve the three pairs of pragmatic functions in their speech: perpetuity and temporariness, subjectivity and objectivity, intentionality and unintentionality. In translation as a translingual speech act, while presenting these couples of pragmatic motivations to a more or less degree, the translator can also attain some other pragmatic functions as expected or unexpected. In light of Croft's prototype theory for syntactic categories and their pragmatic functions, an explication can be made about the pragmatic effects achieved by the re-matching of semantic orientation and syntactic position in C-E translation.

With such pragmatic motives as the three antithetical pairs embraced by the translator as a speech act performer, the maintaining or especially changing of the correlation between semantic orientation and syntactic position in $\mathrm{C}$-E translation can yield the pragmatic consequences. We have two parameters to gauge against pragmatic effects with respect to modifiers. One of them is the prototypicality of the correspondence of the syntactic category to its pragmatic function, i.e., modification, and the other is the substitution of predication for it.

In (10) (11) (12) (13) the original verb-modifiers are rendered into the same syntactic category and thus they do not vary in the degree of prototypicality in terms of their correspondence to the pragmatic function as modification. Both the original and the rendered enjoy the highest prototypicality as far as this correspondence is concerned. In comparison, the Chinese verb-modifiers in (14) (15) (16) are rendered into noun-modifiers relocated into the position before nouns. In accordance with the semantic-syntactic consistency principle, the practice can lend higher prototypicality to the modified and the modified. However, in terms of the relationship between syntactic category and pragmatic function, the English equivalents for “哼哼唧唧," “愤怒,” “愕然” are in the form of the verb's present participle (such as “whimpering”) or past participle (such as "angered," "startled") and thus they are marked due to being coerced into the pragmatic function which they are not supposed to prototypically perform. Then it can be concluded that the translations for the modifiers in (14) (15) (16) are prototypical in terms of semantic-syntactic correlation but less prototypical in terms of category-function correspondence.

The differences between a Chinese modifier and its English counterpart can be teased out with the prototypicality of category-function as one of the gauges for pragmatic effects in the translation of modifiers. Nevertheless, a Chinese modifier and its English counterpart (not necessarily absolute equivalent) can also vary in terms of the substitution of predication prototypically performed by the verb for modification. This variation occurs to the blending of a verb-modifier and the verb, or the verbalizing isolation of a verb-modifier. As the consequence of the merging of the modifier and the modified, the original pragmatic function of modification has faded out, giving way to the function of predication. In the English versions of Chinese sentences (20) (21) (23) (24), the modifying function performed by the original verbmodifier has been replaced by predication, a pragmatic function prototypically performed by verbs, with only hints of semantic remnants left behind. The pragmatic aftermath in the wake of C-E translation is attributed to the linguistic fact that the attractive force of the modifier or the modified overrides the centrifugal force of the 
modified or the modifier. Since the blended verb still contains the semantic properties of the original modifier, such as “stagger” semantically including “东倒西歪," "tap" including "轻轻," the substitution of predication for modification is not as thorough as that happening to the translation in (27) (28) (29), where the modifiers have absolutely isolated themselves from the verb they modify and thus shed their modifying function by achieving a thorough status of predication.

\section{A dependence-theory account for the semantic-syntactic correlation in C-E translation}

In the first part of the essay, we have borrowed from Zhang Guoxian (2005) a pragmatic justification for the shuttle of the positions of verb or noun modifiers in Chinese sentences. Nevertheless, the pragmatic motivations which are employed to justify the removal of a modifier from its semantically oriented verb or noun work most frequently in the construction of spontaneous speech acts. The discourse thus created is closely related to its speaker, who exerts his or her motivation on the construal of the sentence. The positioning of a modifier is put under much more sway of the speaker. But when the spontaneously created sentence is subject to translation, the original context has been removed, and then the translator summons up his or her own motivations to disturb the positioning of modifiers. In a certain sense, we can attribute the relocating of the modifier in translation to the syntactic differences between the two languages. If we resort to this justification, it is no less than canceling the question. We might as well search for the justification from the cognitive perspective.

A lexical unit will be inevitably launched into dependent correlation as soon as it participates in the construction of a sentence. Even when a lexical unit is out of use, it is still potentially in possession of dependent properties. Autonomy is a term employed to characterize the relative independence of a linguistic unit from the others. In terms of autonomy and dependence, "within the class of phonological segments, vowels are clearly autonomous, and consonants dependent." (Langacker 2004: 298) But in the formation of a syllable, a vowel and a consonant are mutually dependent. So autonomy is not an absolute term but rather a relative one. With respect to the relation between autonomy and dependence, semantic-syntactic inconsistence in C-E translation can also be explicated. So far as the degree of dependence is concerned, among the three constituents of a sentential framework, a modifier is the most dependent, a verb is second to a modifier, and a noun is the least dependent. So-called dependence is of both semantic and syntactic significance. A verb is semantically dependent on valences and syntactically dependent on subject, object and complement. A modifier is semantically and syntactically parasitic on entity-noun or action-verb. A noun is not compulsorily dependent on the others though it cannot stand absolutely alone either semantically or syntactically.

However, it is not always the case that what a modifier semantically depends on is the very lexical term it syntactically adheres to. This inconsistence is embodied by the mismatches between semantic orientation and syntactic position. The unsteadiness of a modifier in the relation between semantic and syntactic dependences renders it more susceptible to cross-lingual positional shift in C-E translation. In translation, the occurrence of verb-inclined blending of a modifier and its modified 
implies the highest degree of the dependence of the modifier on the verb it modified. Modifier-inclined blending is attributed to the prevailing of the semantic dependence of the modifier over its syntactic dependence. The semantic dependence is so syntactically susceptible that the proximity between the modifier and the modified verb is easily ruined. Furthermore, in the case of as-inserting shift of a modifier in (27) (28) (29), the loss of the balance in the semantic-syntactic dependence leads to the departing of the modifier from its immediate modified, but the centrifugal force exerted by its semantic dependence is not so great as to pull it apart from the modified as far as it can. They can only be severed up with "as" in between in a compromised way. The uncompromised case of syntactical representation of the semantic dependence of a modifier on its modified is attained by retaking a modifier to the syntactic position before its modified towards which it is semantically oriented. In this way, the semantic dependence runs parallel with the syntactic dependence, as the result of which the syntactic dependence of the modifier on its modified is reduced to none.

\section{Conclusion}

In the process of $\mathrm{C}-\mathrm{E}$ translation, the translator tries to motivate him/herself pragmatically as per the original author. For the positional shift of a modifier, these pragmatic concerns are concretized on the part of the author as three pairs of practical functions: perpetuity and temporariness, intentionality and unintentionality, subjectivity and objectivity. The location and the dislocation of a modifier into or from the position it is or is not supposed to be located at are subject to the influence of these concerns. In general, despite these original pragmatic concerns, in C-E translation the counterpart for an original verb-modifier tends to retrieve the position which guarantees its syntactic vicinity to its semantically oriented entity. However, the pragmatic motivation and the prototypical semantic-syntactic correspondence cannot get away with the actual pragmatic effects embodied by the correspondence between syntactic category and pragmatic function of a modifier.

For Chinese, there is flexibility in the adapting of syntactic location for a modifier to meet the requirement of pragmatic motivation. But in C-E translation, semantic concerns prevail over pragmatic motivations by re-shifting the modifier back into the vicinity of the modified it is semantically oriented to. Although the semantic concerns win over the pragmatic motivations, pragmatic effects are still to be felt in the sense that counterpart modifiers slide along the parameter of prototypicality and the substitution of predication for modification in terms of the category-function interaction. In the original Chinese sentence, semantic orientation, syntactic position and pragmatic function have forged up a relatively stable package of interrelationships. Nevertheless, when the sentence is subjected to translation, the relationship is susceptible to the change of one of the constituents in the package, which will trigger chain effects. As a result, the repackaging of the three constituents is the by-product of the rendered sentence in the target language.

\section{REFERENCES}

Berry, M. (trans.) (2004): Nanjing 1937: A Love Story (Yijiusanqiniandeaiqing by Ye, Zhaoyan), England, Faber and Faber. 
Croft, W. (1991): Syntactic Categories and Grammatical Relations: The Organization of Information, Chicago and London, The University of Chicago Press.

Goldblatt, H. (trans.) (1997): Playing for Thrills (Wandejiushixintiao by Wang, Shuo), New York, William Morrow and Company.

Goldblatt, H. (trans.) (2003): Red Sorghum (Honggaoliangjiazu by Mo, Yan), London, Arrow Books.

Humes, B. (trans.) (2001): Shanghai Baby (Shanghaibaobei by Wei, Hui), New York, Washington Square Press.

Jones, A. F. (trans.) (2004): A Chronicle of Blood Merchant (Xusanguanmaixueji by Yu, Hua), New York, Anchor Books.

Langacker, R. W. (2004): Foundations of Cognitive Grammar I, Beijing, Beijing University Press.

Lu, J. M. (2004): Bashiniandaizhongguoyufayanjiu (Chinese Grammar Studies in the Eighties), Beijing, The Commercial Press.

Lu, J.M. and Shen, Y. (2004): "Zhixianglilunyuyuyizhixiangfenxi" ("Orientation Theory and An Analysis of Semantic Orientation"), Fifteen Lectures on Chinese and Chinese Studies, Beijing, Beijing University Press, pp. 249-295.

Mo, Y. (莫言) (2001): “红高粱家族” (Honggaoliangjiazu), Shijiazhuang, Flower Mountain Arts Press.

Shen, Y. and D. Zheng (eds) (1996): Xiandaihanyudepeijiayanjiu (Studies of Valence Grammar in Modern Chinese), Beijing, Beijing University Press.

WANG, S. （王朔） (2004): “玩得就是心跳”(Wandejiushixintiao), Kunming, Yunnan People Press.

WeI, H. (卫慧) (1999): “上海宝贝”(Shanghaibaobei), Shenyang, Spring Wind Arts Press.

YE, Z.Y. (叶兆言) (2002): “1937年的爱情”(Yijiusanqiniandeaiqing), Changchun, Times Arts Press.

Yu, H. (余华) (2004): “许三观卖血记”(Xusanguanmaixueji), Beijing, People Literature Press.

Zhang, G. X. (2005): “The Semantic Referring Principles of Modifiers and Their Pragmatic Motivations," Chinese Language (Zhongguoyuwen) 1. Beijing, The Commercial Press, pp. 16-28.

Zou, Y. X. (2000): “On Semantic Multi-orientation of Adjective Adverbials," Language (Yuyan) I, Beijing, Capital Normal University, pp. 117-124. 